\title{
Ocean colour opportunities from Meteosat Second and Third Generation geostationary platforms
}

\author{
Ewa J. Kwiatkowska ${ }^{1}$, Kevin Ruddick ${ }^{2}$, Didier Ramon ${ }^{3}$, Quinten Vanhellemont ${ }^{2}$, Carsten Brockmann ${ }^{4}$, \\ Carole Lebreton $^{4}$, and Hans G. Bonekamp ${ }^{1}$ \\ ${ }^{1}$ EUMETSAT, Darmstadt, Germany \\ ${ }^{2}$ Royal Belgian Institute of Natural Sciences, Operational Directorate Natural Environment, Brussels, Belgium \\ ${ }^{3}$ HYGEOS, Lille, France \\ ${ }^{4}$ Brockmann Consult, Geesthacht, Germany \\ Correspondence to: Ewa J. Kwiatkowska (ewa.kwiatkowska@eumetsat.int)
}

Received: 21 September 2015 - Published in Ocean Sci. Discuss.: 21 December 2015

Revised: 21 April 2016 - Accepted: 22 April 2016 - Published: 25 May 2016

\begin{abstract}
Ocean colour applications from mediumresolution polar-orbiting satellite sensors have now matured and evolved into operational services. These applications are enabled by the Sentinel-3 OLCI space sensors of the European Earth Observation Copernicus programme and the VIIRS sensors of the US Joint Polar Satellite System programme. Key drivers for the Copernicus ocean colour services are the national obligations of the EU member states to report on the quality of marine, coastal and inland waters for the EU Water Framework Directive and Marine Strategy Framework Directive. Further applications include $\mathrm{CO}_{2}$ sequestration, carbon cycle and climate, fisheries and aquaculture management, near-real-time alerting to harmful algae blooms, environmental monitoring and forecasting, and assessment of sediment transport in coastal waters. Ocean colour data from polar-orbiting satellite platforms, however, suffer from fractional coverage, primarily due to clouds, and inadequate resolution of quickly varying processes. Ocean colour remote sensing from geostationary platforms can provide significant improvements in coverage and sampling frequency and support new applications and services. EUMETSAT's SEVIRI instrument on the geostationary Meteosat Second Generation platforms (MSG) is not designed to meet ocean colour mission requirements, however, it has been demonstrated to provide valuable contribution, particularly in combination with dedicated ocean colour polar observations. This paper describes the ongoing effort to develop operational ocean colour water turbidity and related products and user services from
\end{abstract}

SEVIRI. SEVIRI's multi-temporal capabilities can benefit users requiring improved local-area coverage and frequent diurnal observations. A survey of user requirements and a study of technical capabilities and limitations of the SEVIRI instruments are the basis for this development and are described in this paper. The products will support monitoring of sediment transport, water clarity, and tidal dynamics by providing hourly coverage and long-term time series of the diurnal observations. Further products and services are anticipated from EUMETSAT's FCI instruments on Meteosat Third Generation satellites (MTG), including potential chlorophyll $a$ products.

\section{Introduction}

There is an established user need for a range of water quality and bio-geochemistry information services for marine, coastal, estuarine and lake environments. These needs are expressed in several user surveys conducted by European Commission projects such as GMES PURE (Albert et al., 2014), MARCOAST (Brockmann et al., 2008; Ruddick et al., 2008), CoBiOS (Kaas and Peters, 2012), and FRESHMON (Stelzer et al., 2011). A critical component of these requirements has been the national obligations of European Union (EU) Member States to report on water quality under the Water Framework Directive (WFD) (European Commission, 2000) and the Marine Strategy Framework Directive (MSFD) (European Commission, 2008). These requirements have guided 
the development of remotely sensed ocean colour products which provide synoptic coverage of a range of water quality and bio-geochemistry indicators. They have also motivated the European Commission's funding of Sentinel-3 satellites as part of the Copernicus Space Component in support of the Copernicus Marine Environment Monitoring Service (CMEMS). Globally, international space agencies, for example in the United States, Japan, Korea, China, India, Brazil, Russia, and Canada, are investing in ocean colour programmes with similar goals.

Ocean colour observations are commonly performed from polar-orbiting satellite platforms which include the Copernicus Sentinel-3 series. Ocean colour coverage from polar observations is, however, significantly reduced due to cloudiness, as well as gaps between orbits and sun glint. For example, polar instruments with data aggregated to $4 \mathrm{~km}$ spatial resolution provide typically between 4 and $8 \%$ coverage of the open ocean per day, depending on the swath width and glint avoidance capabilities (Gregg, 2007). Merger of data from multiple polar missions increases the global coverage but is not straightforward because of differences between instruments (Kwiatkowska and McClain, 2009). High spatiotemporal marine processes thus cannot be adequately resolved by infrequent observations from polar platforms (Antoine et al., 2012; Ruddick et al., 2014).

There is a user need to supplement global polar observations with geostationary ocean colour coverage (Antoine et al., 2012; Albert et al., 2014). The major benefit of geostationary ocean colour is improvement in spatial coverage because frequent daily observations are more likely to record cloudless conditions as shown in Fig. 1 (Ruddick et al., 2014). High-temporal monitoring also gives information on quickly varying processes in coastal oceans, estuarine zones, and lakes which are of special interest to many users (Mouw et al., 2015). The processes include tidal dynamic, eddies, fronts, sediment transport, coastal erosion, river plumes, and hazards such as harmful algal blooms (HAB) and oil spills. It can also provide the required input to coupled models to meet operational needs for marine and coastal nowcasts and forecasts and to improve model variability at intra-seasonal and inter-annual timescales. Neukermans et al. (2009) first demonstrated the potential of geostationary ocean colour remote sensing to capture the tidal variability of suspended sediments with the Spinning Enhanced Visible and InfraRed Imager (SEVIRI). Subsequently, the first ocean colour instrument on a geostationary platform was successfully demonstrated by the Korea Institute of Ocean Science and Technology (KIOST) (Choi et al., 2012; Ryu et al., 2012). KIOST's Geostationary Ocean Color Imager (GOCI) provides $2500 \mathrm{~km} \times 2500 \mathrm{~km}$ coverage in hourly intervals centred on the Korean peninsula and the followon mission, GOCI-II, will also support Full Disk coverage (Park, 2015). It has been shown that recurrent daily observations from a geostationary platform significantly increase the coverage of water quality and bio-geochemical processes

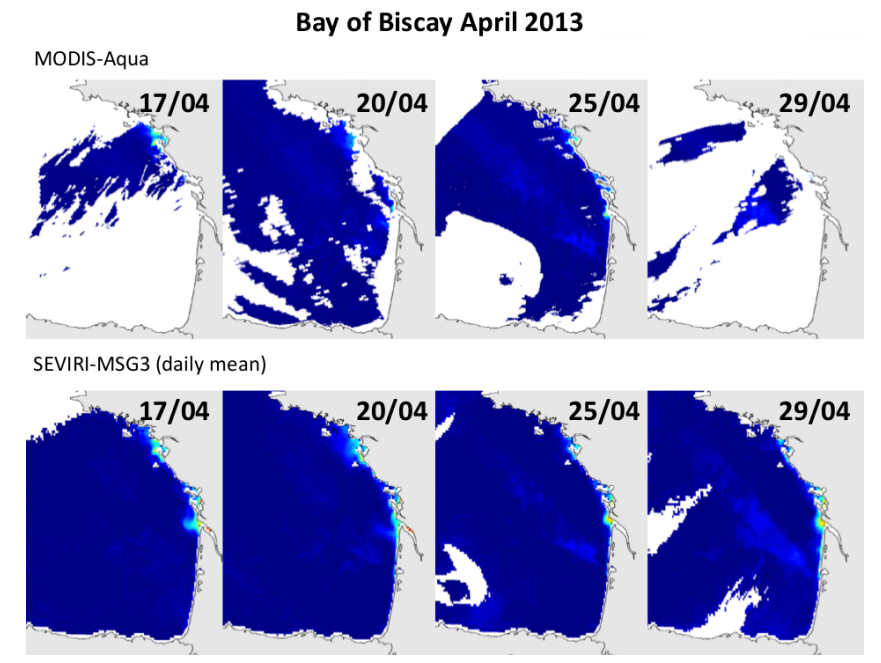

Figure 1. Sequence of daily observations of the Bay of Biscay by NASA's polar-orbiting MODIS sensor on the Aqua platform and by SEVIRI on MSG3. Development of coccolithophore blooms can be clearly followed on the SEVIRI daily mean images of the red marine remote sensing reflectance. The figure is reproduced from Vanhellemont et al. (2013).

(Wang et al., 2013). GOCI provides a three-fold improvement in coverage based on its acquisition of 8 scenes per day in comparison with a single daily acquisition. GOCI applications include fishing ground index, HAB index, underwater visibility, surface current vectors, water quality index and primary productivity.

EUMETSAT operates a series of geostationary platforms called Meteosat Second Generation (MSG) which carry Spinning Enhanced Visible and InfraRed Imagers (SEVIRI) with solar bands in the range of 635,810 , and $1640 \mathrm{~nm}$, as shown in Table 1 (Schmetz et al., 2002). SEVIRI is not an ocean colour instrument. It has reduced spectral and spatial resolution and a degraded signal-to-noise ratio compared to standard ocean colour missions (Govaerts and Clerici, 2004; Antoine et al., 2012). SEVIRI's bands in the red and near-infra-red (NIR) spectra only allow for a limited range of water quality and bio-geochemistry products, those associated with suspended sediments, turbidity and extremely high plankton biomass. Only high-turbidity bright targets can be distinguished, with remote sensing reflectances above $0.001 \mathrm{sr}^{-1}$ in the red. SEVIRI's spatial resolution of $3 \mathrm{~km}$ at nadir results in coarser spatial resolution over Europe: for example, $6 \mathrm{~km}$ resolution in the southern North Sea. Nonetheless, SEVIRI has been shown to provide a useful contribution to ocean colour observations. Figure 2 shows the East Anglian plume detected by SEVIRI, a region of relatively high concentrations of suspended sediments which constitutes a major feature transporting sediment across the North Sea (Dyer and Moffat, 1998). SEVIRI's frequent imaging every $15 \mathrm{~min}$ has been demonstrated to improve temporal cover- 


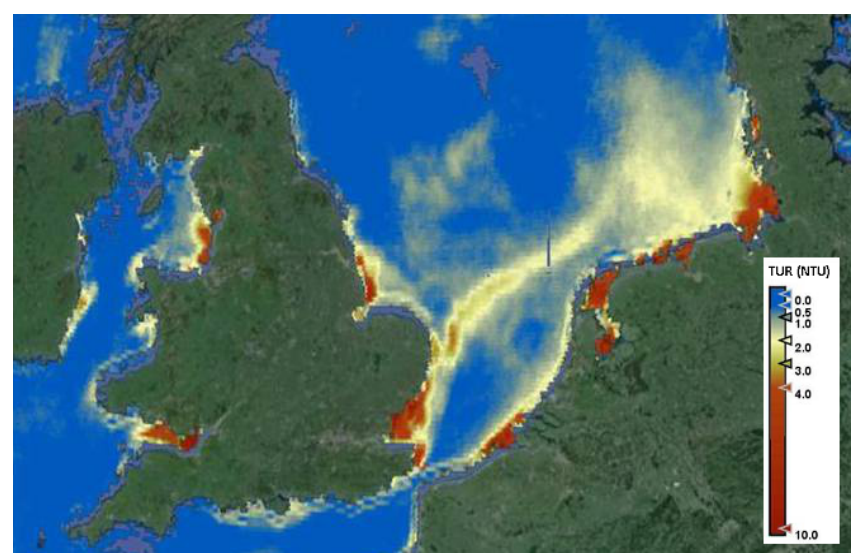

Figure 2. East Anglian plume from MSG-2 SEVIRI. A monthly mean of SEVIRI water turbidity for July 2008 is depicted. Turbidity is expressed in the nephelometric turbidity unit.

age of coastal water clarity, tidal effects and sediment transport (Ruddick et al., 2014; Neukermans et al., 2012). SEVIRI has also been found capable of distinguishing specific biogeochemical features, such as coccolithophore blooms as, for instance, demonstrated in the Bay of Biscay (Vanhellemont et al., 2013) and displayed in Fig. 1.

EUMETSAT's Meteosat Third Generation (MTG) Imaging satellites, with the first of the series planned for launch in 2020, will carry Flexible Combined Imager (FCI) instruments which are the upgraded continuation of MSG SEVIRI (EUMETSAT, 2015). FCI instruments will operate additional spectral bands in the visible blue and green wavelengths, 444 and $510 \mathrm{~nm}$, as shown in Table 2, that are potentially suitable for additional ocean colour products of which the most important are chlorophyll $a$ concentrations. Frequent imaging of the Full Disk every 10 min has the potential to further improve spatial and temporal coverage of marine, coastal, estuarine and lake bio-geochemical processes. The spatial resolution of $1 \mathrm{~km}$ at nadir is an enhancement on SEVIRI's $3 \mathrm{~km}$ resolution and it is suitable for open ocean observations, as well as providing meaningful improvement for coastal and lake studies.

This paper describes the ongoing effort to develop operational ocean colour products and data services from EUMETSAT's geostationary missions. Current work focuses on user requirements and scientific constraints.

\section{User requirements towards SEVIRI ocean colour products}

This review of user requirements for geostationary operational ocean colour products includes outcomes of the European Commission projects, like GMES PURE, MarCoast, CoBiOS, and FRESHMON (Albert et al., 2014; Brockmann et al., 2008; Kaas and Peters, 2012; Stelzer et al., 2011). The sources further incorporate existing user requirements from the CMEMS predecessor, European Commission project MyOcean, as well as the documentation from the Committee on Earth Observation Satellites Ocean Colour Radiometer Virtual Constellation (CEOS OCR-VC, 2013), and International Ocean Colour Coordinating Group and International Ocean Colour Science meetings (Antoine et al., 2012; IOCS, 2013, 2015). Evolving and emerging user requirements were also collected via additional user questionnaires and interactions conducted during the current study. The questionnaires addressed experts in national institutes charged with documenting and managing regional water quality, commercial operators cooperating with national institutes, as well as scientific users of the data.

SEVIRI's full disk coverage provides observations over Europe and Africa, therefore user requirements from both continents have been compiled in the course of the current study. In Europe, the requirements are largely driven by the EU directives, WFD and MSFD (European Commission, 2000, 2008). The directives call for monitoring of coastal and marine water quality. The WFD also requests the monitoring of inland lakes as well as rivers, transitional waters, nearshore waters and groundwater bodies. In Africa, monitoring of coastal water quality and quality of African lakes is of high priority but less formalized. Further applications include sediment transport, ecosystem modelling, offshore operations, and carbon burial by coccolithophores.

Several user requirements cannot be met by the SEVIRI and FCI instruments alone because of their spectral, radiometric and spatial limitations. This paper restricts the description and analysis of user requirements to those that are feasible for SEVIRI and FCI. SEVIRI and FCI will not push ocean colour state-of-the-art. However, they could provide unique diurnal coverage above Europe and Africa which would benefit many users and services and which could be used in combination with dedicated ocean colour polar observations.

\subsection{Water resource monitoring in response to European Union directives}

For European coastal waters, only MSFD is of relevance to SEVIRI because WFD focuses on waters within "1 nautical mile" of the coast which are impossible to observe with the coarse SEVIRI spatial resolution. The main goal of the MSFD is to achieve Good Environmental Status of EU marine waters by 2020. The Directive defines Good Environmental Status (GES) as "The environmental status of marine waters where these provide ecologically diverse and dynamic oceans and seas which are clean, healthy and productive" (European Commission, 2008, Article 3). MSFD defines GES via 11 qualitative descriptors of which the most relevant to SEVIRI are three: eutrophication and associated high algal biomass; hydrographical conditions and the turbidity parameter related to the load of suspended particu- 
Table 1. MSG SEVIRI solar-reflective spectral bands.

\begin{tabular}{llll}
\hline $\begin{array}{l}\text { MSG SEVIRI } \\
\text { Spectral bands }\end{array}$ & $\begin{array}{l}\text { Central } \\
\text { wavelength }\end{array}$ & $\begin{array}{l}\text { Wavelength } \\
\text { range }\end{array}$ & $\begin{array}{l}\text { Spatial resolution } \\
\text { at nadir }\end{array}$ \\
\hline VIS 0.6 & $635 \mathrm{~nm}$ & $560-710 \mathrm{~nm}$ & $3 \mathrm{~km} \times 3 \mathrm{~km}$ \\
NIR 0.8 & $810 \mathrm{~nm}$ & $740-880 \mathrm{~nm}$ & $3 \mathrm{~km} \times 3 \mathrm{~km}$ \\
SWIR 1.6 & $1640 \mathrm{~nm}$ & $1500-1780 \mathrm{~nm}$ & $3 \mathrm{~km} \times 3 \mathrm{~km}$ \\
HRV (High-resolution visible) & $750 \mathrm{~nm}$ & $370-1250 \mathrm{~nm}$ & $1 \mathrm{~km} \times 1 \mathrm{~km}$ \\
\hline
\end{tabular}

Table 2. MTG FCI solar-reflective spectral bands.

\begin{tabular}{llll}
\hline $\begin{array}{l}\text { MTG FCI } \\
\text { Spectral bands }\end{array}$ & $\begin{array}{l}\text { Central } \\
\text { wavelength }\end{array}$ & $\begin{array}{l}\text { Spectral } \\
\text { width }\end{array}$ & $\begin{array}{l}\text { Spatial resolution } \\
\text { at nadir }\end{array}$ \\
\hline VIS 0.4 & $444 \mathrm{~nm}$ & $60 \mathrm{~nm}$ & $1 \mathrm{~km} \times 1 \mathrm{~km}$ \\
VIS 0.5 & $510 \mathrm{~nm}$ & $40 \mathrm{~nm}$ & $1 \mathrm{~km} \times 1 \mathrm{~km}$ \\
VIS 0.6 & $640 \mathrm{~nm}$ & $50 \mathrm{~nm}$ & $1 \mathrm{~km} \times 1 \mathrm{~km}$, \\
& & & $0.5 \mathrm{~km} \times 0.5 \mathrm{~km}$ \\
NIR 0.8 & $865 \mathrm{~nm}$ & $50 \mathrm{~nm}$ & $1 \mathrm{~km} \times 1 \mathrm{~km}$ \\
NIR 0.9 & $914 \mathrm{~nm}$ & $20 \mathrm{~nm}$ & $1 \mathrm{~km} \times 1 \mathrm{~km}$ \\
SWIR 1.3 & $1380 \mathrm{~nm}$ & $30 \mathrm{~nm}$ & $1 \mathrm{~km} \times 1 \mathrm{~km}$ \\
SWIR 1.6 & $1610 \mathrm{~nm}$ & $50 \mathrm{~nm}$ & $1 \mathrm{~km} \times 1 \mathrm{~km}$ \\
SWIR 2.2 & $2250 \mathrm{~nm}$ & $50 \mathrm{~nm}$ & $1 \mathrm{~km} \times 1 \mathrm{~km}$, \\
& & & $0.5 \mathrm{~km} \times 0.5 \mathrm{~km}$ \\
\hline
\end{tabular}

late matter; and biodiversity. The eutrophication descriptor includes two indicators which are measurable by optical remote sensing, these are chlorophyll $a$ concentrations over the algae growing season, and water transparency related to the increase in suspended algae (Sanden and Håkansson, 1996). For these indicators, SEVIRI's use in combination with data from dedicated polar-orbiting missions shows the most capabilities (Ruddick et al., 2014). SEVIRI data alone provide the transparency indicator in turbid waters via the Secchi depth and could potentially support identification of the most extreme high-biomass algal blooms. Chlorophyll $a$ concentration could not be obtained from SEVIRI but may be supported by MTG FCI instruments. The hydrographical condition descriptor requires monitoring of turbidity or suspended particulate matter indicators which can be provided by both the SEVIRI and FCI instruments. SEVIRI and FCI can provide the spatial extent and the temporal resolution required by the directive. Product time series can be made available over many years or even decades for trend identification. The spatial resolution of SEVIRI in European waters allows adequate monitoring of offshore zones, but still presents challenges in coastal waters. Coastal studies will benefit more from the FCI instrument.

For European lakes, WFD defines plankton and general hydromorphological condition parameters which are relevant to SEVIRI and FCI. Out of these parameters, water turbidity and/or transparency (measureable via Secchi depth) are already observable from SEVIRI, while additional plankton concentrations can be supported by FCI. Massive blooms of cyanobacteria, surface blooms and scums of cyanobacteria are also relevant for WFD and could possibly be flagged using SEVIRI. An obvious limitation of SEVIRI for inland water applications is the spatial resolution. Only the very largest European lakes are observable, including Lake Balaton (max. length $77 \mathrm{~km}$, max. width $14 \mathrm{~km}$ ), Lake Geneva $(73,14 \mathrm{~km})$ and the Bodensee/Lake Constance $(63,14 \mathrm{~km})$. The increased resolution of the FCI instrument will support coverage of additional lakes because FCI's $1 \mathrm{~km}$ spatial resolution at nadir will result in about 2 to $3 \mathrm{~km}$ resolution over Europe.

\subsection{African water resource monitoring}

In African coastal and inland waters the environmental problems are often more acute than in Europe in their affects on human health and food supply (e.g. fisheries, aquaculture). Rio de Janeiro's United Nations Conference on Environment and Development of 1992 has generated international interest in preservation of biodiversity in Africa (UN, 1992). In particular, EUMETSAT has a long-standing commitment to cooperate with Africa in the frame of the World Meteorological Organization strategic plan and multiple European Union programmes. The programmes started in 2001 with the Preparation for the Use of Meteosat Second Generation in Africa (PUMA) and now are extended with ocean colour applications within the Copernicus/EC framework. The programmes include GEONETCast applications for and by Developing Countries (DevCoCast) and the Europe-Africa Marine Network (EAMNET). Further projects are the European 
Space Agency's TIGER initiative to promote the use of Earth Observation for improved integrated water resources management in Africa. The extension of SEVIRI capabilities with ocean colour addresses new African user needs and fits well into this development.

The identified African user needs are tracking of harmful algal blooms and monitoring of water quality. Further needs address eutrophication, water transparency, detecting extreme high-biomass or cyanobacteria blooms, scums and floating vegetation like intensive proliferation of water hyacinths (Eichhorna crassipes) in lakes. In coastal regions, it is also required to monitor sediment transport, underwater visibility for maritime operations, and high-frequency physical/biological processes.

Geostationary spatial resolution over Africa is better than over Europe; thus, SEVIRI is useful for offshore, coastal and lake applications and FCI promises even better coverage and additional products. The lakes that can be monitored with SEVIRI at resolutions close to $3 \mathrm{~km}$ include Lake Victoria/Nam Lolwe/Nalubaale (max. length $337 \mathrm{~km}$, max. width $250 \mathrm{~km})$, Lake Tanganyika $(673,72 \mathrm{~km})$ and Lake Malawi/Nyassa $(560,75 \mathrm{~km})$. SEVIRI can deliver over a decadal product time series for trend analysis.

\subsection{Additional user requirements}

User needs also address transport of sediments in coastal waters - something which is of the major interest to coastal zone managers because of changes in bathymetry. Sediment transport is critical for waterway navigation, offshore construction, and for the understanding of coastal erosion and sedimentation that affect flooding defences, real estate, recreation and aquaculture. SEVIRI and FCI can provide relevant turbidity and/or suspended particulate matter concentration products. The spatial resolution required is highly dependent on the specific application. For example, sediment transport in the vicinity of offshore structures or ports may involve processes at the scales of metres or tens of metres (Vanhellemont and Ruddick, 2014). On the other hand, sediment transport models have typical resolutions of $100 \mathrm{~m}-10 \mathrm{~km}$, with the coarser-resolution models being used for large-scale transport, e.g. at the scale of the southern North Sea. The temporal resolution required for sediment transport applications in regions of tidal variation is typically hourly, which is suitable for both SEVIRI and FCI instruments.

Ecosystem modelling is another application. It has been driven by the need to manage eutrophication and water quality (Lenhart et al., 2010). The models use sunlight and nutrient load-up, where light is represented by scalar quantum photosynthetically available radiation (PAR: $400-700 \mathrm{~nm}$ ) and its vertical attenuation in the water column (KdPAR) or by an equivalent parameter, such as euphotic depth. SEVIRI can only support parameterization of the attenuation coefficient in turbid waters in which non-algal particles (NAP) are the dominant factor determining algal bloom timing and duration. FCI can improve on this and also incorporate attenuation due to phytoplankton. SEVIRI and FCI can resolve high-frequency tidal and diurnal processes such as the timing of tidal resuspension/advection with respect to the sunlight maximum. In an ecosystem model, these processes have been demonstrated to modify the net effect of light on photosynthesis compared to daily averaged values (Desmit et al., 2005). Most ecosystem models have spatial resolutions similar to the SEVIRI resolution.

Diving operations in context of offshore constructions and environmental monitoring are identified as another user niche which can be supported by horizontal visibility or turbidity products. SEVIRI high-frequency data are well suited for defining optimal time windows for diving, which typically last $1-3 \mathrm{~h}$ because of tidal variability, while FCI will improve on the spatial coverage.

Coccolithophores are a class of calcifying phytoplankton of particular interest to global climate change, both past (de Vargas et al., 2007) and future, because of their role in oceanic inorganic carbon chemistry, their sensitivity to oceanic acidity (Smith et al., 2012) and for their importance in the long-term sink of carbon via sedimentation and burial (Milliman, 1993). Coccolithophores are distinguished by a covering of calcium carbon plates known as coccoliths which are highly reflective, thus making this species easily visible from space during blooms (Groom and Holligan, 1987). SEVIRI can detect the strongest coccolithophore blooms, mark their extent as the blooms are generally large scale, and map them with frequent imagery. A coccolithophore bloom flag and red marine reflectance are feasible products from SEVIRI. The FCI instrument will be able to distinguish coccolith concentrations.

Users have also identified the SEVIRI red marine reflectance and its particulate backscattering as parameters defining diurnal variability of individual marine, coastal and lake waters. Knowledge of this variability can facilitate improved calibration and validation protocols, such as matchups between satellite and in situ measurements and satellite to satellite matchups.

Absorption coefficients of algal pigments and of coloured dissolved organic matter have also been recommended but may only be possible from FCI. Furthermore, increasing user interest has been recorded in more complex ocean colour parameters, such as phytoplankton functional types. These parameters are however difficult from the instruments not devoted to ocean colour.

\subsection{Summary product requirements}

Table 3 summarizes ocean colour applications feasible from the SEVIRI instruments which have been requested through user surveys. Table 4 lists the corresponding SEVIRI and FCI products. Concerning product requirements, most applications call for spatial resolutions better than SEVIRI's within a range of several hundreds of meters to a few meters. Accu- 


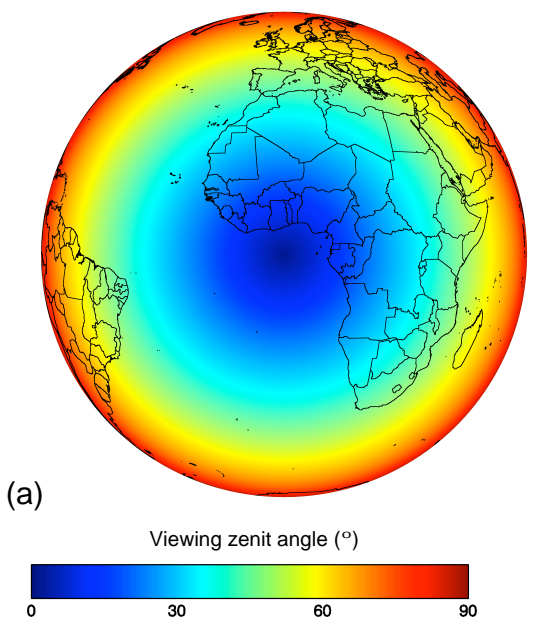

(b)

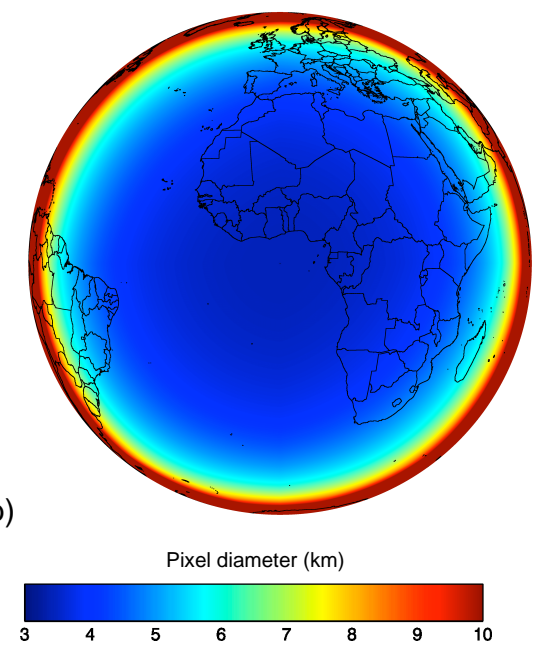

Figure 3. Area visible from SEVIRI at $\left(0^{\circ} \mathrm{N}, 0^{\circ} \mathrm{E}\right)$ : (a) view zenith angles, and (b) pixel spatial resolution.

racies for the products are difficult to obtain, although most users recognize validation and product confidence as being highly important. The accuracy label classified as "threshold" must pass certain threshold criteria, "absolute" must provide quantitative accuracy measures and "scientifically sound" has no accuracy requirements, but the algorithm must be validated. A need for near-real-time (NRT) product dissemination is not identified, except for a few applications including extreme high-biomass HABs, planning of offshore diving activities, and certain short-range ecosystem models. Important for most applications is however the availability of multi-year historical data.

User-requested products that could be additionally obtained from FCI instruments include chlorophyll $a$ concentrations, absorption coefficients at $443 \mathrm{~nm}$ of algal pigments and coloured dissolved organic matter, and diffuse attenuation coefficient spectrum.

\section{Scientific constraints of ocean colour SEVIRI and FCI products}

To address user requirements, geostationary ocean colour processing must meet operational constraints over the Earth disk coverage and must be capable of providing a stable product time series.

Scientific development of these products and services has to account for a number of differences between ocean colour data acquired from polar and geostationary orbits. One of the most impacting factors is that geostationary observations provide Earth disk coverage in which spatial resolution and viewing geometries expand significantly towards the disk's edges, as displayed in Fig. 3. Figure 3a shows that viewing geometries exceed $60^{\circ}$ in large parts of Europe. This poses significant challenges for ocean radiometric retrievals, particularly for atmospheric correction and air-sea interface mod- elling (Ruddick et al., 2014). Furthermore, the fact that SEVIRI and FCI instruments are not designed to meet ocean colour requirements causes additional product limitations. An important part of the development is therefore the characterization of the limitations of operational ocean colour product quality.

\subsection{Algorithmic and instrument limitations}

For geostationary ocean colour products, atmospheric corrections exceed current processing specifications at high air masses, typically beyond the factor of 4 , and necessitate using spherical shell atmosphere models (Ding and Gordon, 1994). High sun zenith angles result in weak sunlight transmittance to the surface (Wang, 2006). High viewing zenith angles cause strong skylight reflection (Ruddick et al., 2014) and weak sea-air interface transmittance and, in turn, produce a weak water-leaving signal. Most ocean colour data processing algorithms are not designed to function for viewing zenith angles greater than $60^{\circ}$, but such viewing angles become important for high-latitude remote sensing from geostationary platforms (see Fig. 3). Slant geometries amplify uncertainties associated with Rayleigh-aerosol interactions and decoupling of atmospheric gas layers like ozone. Effects of bright targets such as land or clouds that are adjacent to the water surface are extended over larger distances. High wind speeds cause additional uncertainties, particularly for correction of skylight reflected at the air-sea interface at high viewing zenith angles.

SEVIRI and FCI characteristics put further constraints on ocean colour products. SEVIRI is hindered by its spectral resolution because the red and NIR bands only enable a restricted range of products that are mostly defined by water turbidity. FCI's additional bands in the blue and green will improve on this and may enable chlorophyll-related products. Most ocean colour coastal and inland water applications 
Table 3. Summary of SEVIRI ocean colour applications requested by users.

\begin{tabular}{llll}
\hline Application & Products & Spatial Res. & Temporal \\
\hline Coastal water quality - Europe (MSFD) & TUR, SPM, SD & $300 \mathrm{~m}-1 \mathrm{~km}$ & $1 \mathrm{~h}-10 \mathrm{yr}+$ \\
Water quality of European lakes (WFD) & TUR, SD, XCYA & $300 \mathrm{~m}-1 \mathrm{~km}$ & $1 \mathrm{~h}-10 \mathrm{yr}+$ \\
Coastal water quality - Africa & TUR, SD, XHAB & $\sim 1 \mathrm{~km}$ & $1 \mathrm{~h}-10 \mathrm{yr}+, \mathrm{NRT}$ \\
Water quality of African lakes & TUR, SD, XCYA & $300 \mathrm{~m}-1 \mathrm{~km}$ & $1 \mathrm{~h}-10 \mathrm{yr}+$ \\
Sediment transport & TUR, SPM & $10 \mathrm{~m}-1 \mathrm{~km}$ & $1 \mathrm{~h}-10 \mathrm{yr}+$ \\
Ecosystem modelling (eutrophication) & KdPAR/Ze, SPM & $1-10 \mathrm{~km}$ & $1 \mathrm{~h}-10 \mathrm{yr}+, \mathrm{NRT}$ \\
Offshore diving operations & TUR (HVIS) & $1-100 \mathrm{~m}$ & $10 \mathrm{~min}-6 \mathrm{~h}, \mathrm{NRT}$ \\
Carbon burial by coccolithophores & COCCO & $\sim 10 \mathrm{~km}$ & $1 \mathrm{~h}-10 \mathrm{yr}+$ \\
Support for ocean colour validation & $R_{\mathrm{rs}}, b_{\mathrm{bp}} 640$ & $300 \mathrm{~m}-1 \mathrm{~km}$ & $5 \mathrm{~min}-10 \mathrm{yr}+$ \\
\hline
\end{tabular}

Table 4. Listing of SEVIRI and FCI ocean colour products requested by users.

\begin{tabular}{llll}
\hline SEVIRI and FCI products & Unit & Symbol & Accuracy \\
\hline Water-leaving remote sensing reflectance $640 \mathrm{~nm}$ & $\mathrm{sr}^{-1}$ & $R_{\mathrm{rs}}$ & Absolute \\
Suspended particulate matter & $\mathrm{g} \mathrm{m}^{-3}$ & $\mathrm{SPM}$ & Threshold \\
Turbidity & $\mathrm{NTU}$ & $\mathrm{TUR}$ & Absolute \\
Particulate backscatter at $640 \mathrm{~nm}$ & $\mathrm{~m}^{-1}$ & $b_{\mathrm{bp}} 640$ & Absolute \\
Secchi depth & $\mathrm{m}^{-1}$ & $\mathrm{SD}$ & Threshold \\
Diffuse attenuation coefficient of PAR in turbid waters & $\mathrm{m}^{-1}$ & KdPAR & Absolute, uncertainty \\
& & & per pixel \\
Euphotic depth & $\mathrm{m}$ & $\mathrm{Ze}$ & Absolute, uncertainty \\
& & & per pixel \\
Coccolithophore bloom & $\mathrm{Flag}$ & $\mathrm{COCCO}$ & Scientifically sound \\
Extreme High Biomass algal bloom & $\mathrm{Flag}$ & XHAB & Scientifically sound \\
Extreme cyanobacteria bloom/surface scum/vegetation & $\mathrm{Flag}$ & XCYA & Scientifically sound \\
\hline FCI products & $\mathrm{Unit}^{2}$ & Symbol & Accuracy \\
\hline Chlorophyll $a$ concentration & $\mathrm{mg} \mathrm{m}^{-3}$ & chlor $a$ & Absolute \\
Algal pigment absorption coefficient at $443 \mathrm{~nm}$ & $\mathrm{~m}^{-1}$ & $a_{\text {pig }} 443$ & Absolute \\
CDOM absorption coefficient at $443 \mathrm{~nm}$ & $\mathrm{~m}^{-1}$ & $a_{\mathrm{CDOM}} 443$ & Absolute \\
Diffuse attenuation coefficient spectrum & $\mathrm{m}^{-1}$ & Kd & Absolute \\
\hline
\end{tabular}

require spatial resolution significantly higher than SEVIRI's, as seen from the user requirements. This is highlighted in Fig. 3b. SEVIRI's high-resolution visible (HRV) $1 \mathrm{~km}$ band is therefore investigated here for the possibilities of image sharpening. SEVIRI signal-to-noise ratios (SNR) are low compared to the SNR requirements of sensors dedicated to ocean colour observations (Govaerts and Clerici, 2004; McClain and Meister, 2012). To improve on the product quality, SNR are improved by accumulating $15 \mathrm{~min}$ data to the hourly products. SEVIRI absolute calibration and characterization are also limited with biases estimated at $-8,-6$ and $+3.5 \%$ in bands at 635,810 , and $1640 \mathrm{~nm}$, respectively; with these estimates having uncertainties of 1 to $1.5 \%$ (Meirink et al., 2013). An example of the impact of $1 \%$ absolute uncertainty in band $0.6 \mu \mathrm{m}$ on water-leaving reflectances is shown in Fig. 4. To mitigate, the radiometric biases are corrected using established vicarious calibration methods (Wagner et al., 2012).
Due to these limitations, SEVIRI can only quantify strong marine optical signals beyond $0.001 \mathrm{sr}^{-1}$ in the red remote sensing reflectance and can only observe corresponding high-turbidity waters and very high-biomass algal blooms. FCI will add the opportunity to monitor clear-water open seas. FCI's processing will use similar approaches to ease the instrument limitations, including spatial resolution sharpening with $500 \mathrm{~m}$ bands, increasing SNR via hourly product averaging, and radiometric vicarious calibration.

The existing ocean colour uncertainty requirements are defined for clear and low-turbidity waters (McClain and Meister, 2012; Donlon, 2011) and the user surveys conducted in the course of this study have not obtained definitive SEVIRI uncertainty specifications. This study therefore aims to estimate product uncertainties through the process of comprehensive validations. The validations will provide the uncertainties for users to decide on the usage of the products in their specific applications. 


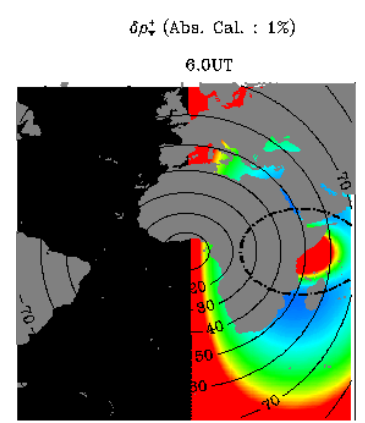

$10.5 \mathrm{UT}$

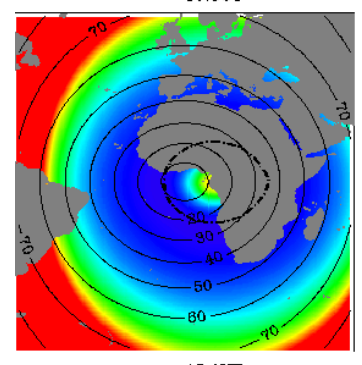

15.0UT

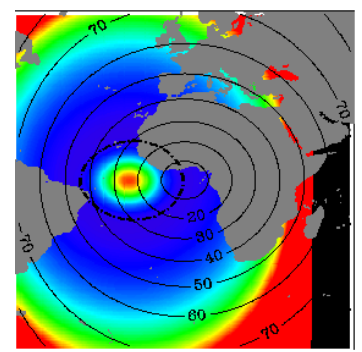

$\rho_{\pi}^{+}(665 \mathrm{~nm})=0.0030 ; \tau_{\mathrm{a}}(865 \mathrm{~nm})=0.04 ; w_{\mathrm{a}}=5.0\left(\mathrm{~m} \mathrm{~s}^{-1}\right)$

$7.5 \mathrm{UT}$

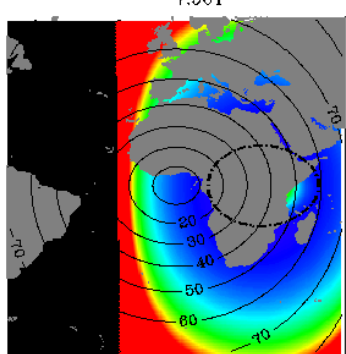

12.0 DT

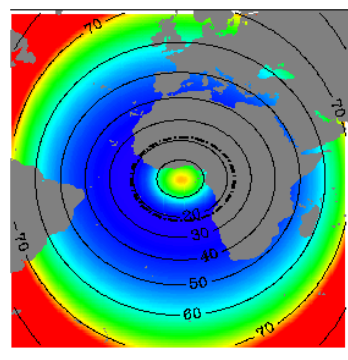

16.5UT

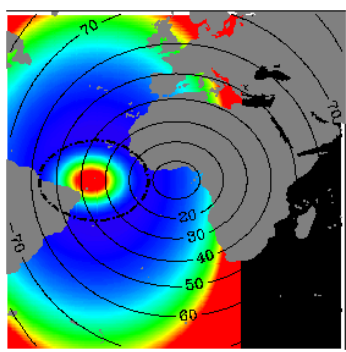

$9.0 \mathrm{UT}$

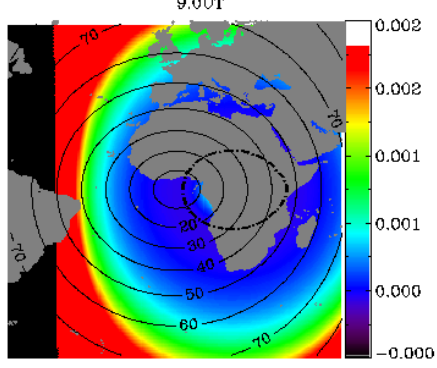

$13.5 \mathrm{UT}$

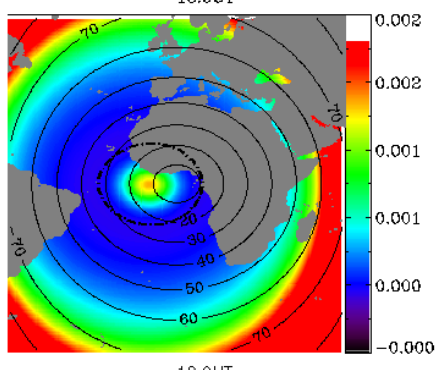

$18.0 \mathrm{UT}$

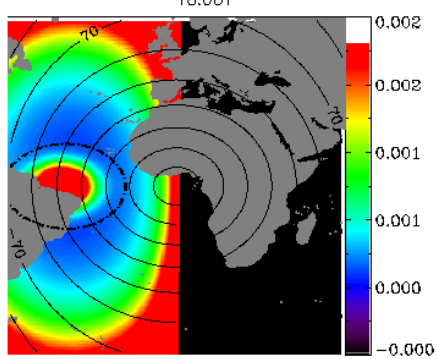

Figure 4. Absolute errors in water-leaving reflectances caused by $1 \%$ absolute calibration error in the $665 \mathrm{~nm}$ band. The assumed water reflectance is 0.003 , aerosol optical depth is 0.04 , the wind speed is $5 \mathrm{~m} \mathrm{~s}^{-1}$, and the time of the year is the spring equinox.

\subsection{Summary of the algorithmic approach}

In SEVIRI ocean colour development, the algorithmic approach largely follows previous work by Neukermans et al. $(2009,2012)$ and focuses on operational processing capacity over the full SEVIRI disk coverage. The processing stages include top-of-the-atmosphere re-calibration, dedicated atmospheric correction and application of basic inwater algorithms. The major modifications occur in the application of the spherical shell atmosphere for the modelling of Rayleigh molecular scattering, and in the automated extrapolation of aerosol properties derived for clear waters to adjacent turbid regions. The SWIR $1.640 \mathrm{~nm}$ band is also investigated for aerosol modelling in combination with a strategy to increase its SNR via temporal averaging. If the main aerosol approaches fail for a given pixel, the atmospheric correction resorts to using aerosol monthly climatology. The SEVIRI HRV band is used for its capacity to increase the product spatial resolution, again, in combination with temporal averaging to increase its SNR.

FCI atmospheric correction could use NIR/SWIR bands in open sea and modified NIR and SWIR band approaches in relatively turbid coastal and inland waters (Gordon and Wang, 1994; Wang and Shi, 2007; Jiang and Wang, 2014). For in-water constituents, including chlorophyll $a$ concentrations, inherent optical property algorithms are expected to assure smooth transitions from open sea to coastal waters (Werdell et al., 2013).

Major product limitations due to retrieval and instrument conditions are summarized in Table 5. The largest errors arise at high air masses, in the sun-glint geometry, and at high aerosol optical depth conditions.

\section{Conclusions}

User requirement studies point to high interest in ocean colour products from geostationary platforms. There is a well-defined need to increase the spatial extent of coverage of aquatic processes and to capture diurnal cycles in coastal, estuarine and inland-water environments which are currently undersampled by polar-orbiting sensors (Mouw et al., 2015). The ongoing effort to develop operational water turbidity products from EUMETSAT's SEVIRI instruments serves to 
Table 5. Summary of conditions contributing to SEVIRI ocean colour product uncertainties, where the largest errors arise at high air masses, in the sun-glint geometry and at high aerosol optical depths.

\begin{tabular}{ll}
\hline SEVIRI product & Uncertainty \\
\hline Gaseous transmission & Low to moderate \\
\hline $\begin{array}{l}\text { Air-sea interface: ocean albedo } \\
\text { modelling }\end{array}$ & Low to significant, depending on a surface model \\
\hline $\begin{array}{l}\text { Air-sea interface: wind speed } \\
\text { impact on glint }\end{array}$ & $\begin{array}{l}\text { Low to moderate at moderate viewing zenith angles }\left(<60^{\circ}\right) ; \\
\text { high to very high for high viewing zenith angles }\left(60-75^{\circ}\right)\end{array}$ \\
\hline Adjacency effects & $\begin{array}{l}\text { Large for sight paths over land } \leq 15 \mathrm{~km} \text { and sand } / \mathrm{snow} / \mathrm{ice} \\
\text { surfaces, strongest at } 0.8 \mu \mathrm{m}\end{array}$ \\
\hline Absolute calibration & Need for vicarious adjustment \\
\hline SNR & $\begin{array}{l}\text { Impact on detection limit, need for temporal averaging, } \\
\text { extended averaging needed for } 1640 \mathrm{~nm} \text { and HRV }\end{array}$ \\
\hline Inter-band registration & Low to moderate at high air masses \\
\hline Atmospheric sphericity & Moderate at high air masses \\
\hline Inter-band calibration & Strong impact on extrapolation of aerosol spectral properties \\
\hline
\end{tabular}

meet these needs and to investigate geostationary capabilities in anticipation of future dedicated ocean colour missions.

The concept of geostationary ocean colour already has broad coverage in the literature with thorough descriptions of user needs, applications, and mission characteristics (Antoine et al., 2012; Albert et al., 2014; Ruddick et al., 2014; He et al., 2013). The first dedicated geostationary ocean colour mission is now in space, GOCI from Korea, while GOCIII is in development. A number of other agencies have their respective missions in stages of preliminary analyses. Proof of concept water turbidity products have been successfully demonstrated from SEVIRI (Neukermans et al., 2012) and shown to significantly improve the coverage of aquatic processes and to enable tracking of high spatio-temporal events thanks to frequent observations during the day.

This current work extends the existing recommendations and research to develop an operational ocean colour capability based on SEVIRI. The survey of user requirements suggests that despite many SEVIRI limitations, turbidity-related products will be useful for user reporting within the European MSFD and WFD, for monitoring of coastal water quality and quality of lakes in Africa, and for further applications including sediment transport, ecosystem modelling, offshore operations, and coccolithophore observations. The FCI instrument on MTG will improve on SEVIRI's capabilities and enable higher spatial-resolution observations and additional products such as possible chlorophyll $a$ quantification.

The goal of the SEVIRI's ocean colour processor is to provide NRT capabilities so that it can be extended to the operational SEVIRI processing chain. The goal is also to reprocess multi-year and multi-mission SEVIRI data time series to provide the long-term turbidity trends required by many applica- tions. SEVIRI algorithm development follows the published research (Neukermans et al., 2012). Additionally, it extends the turbidity products over the Earth disk coverage and incorporates the product error budget due to modelling uncertainties at large solar and viewing zenith geometries and due to the actual spectral, spatial, and radiometric limitations of the sensor. User requirements have added new products to the development: water-leaving remote sensing reflectance, Secchi depth, horizontal visibility, and flagging of extreme high biomass algal blooms and of extreme cyanobacteria blooms, surface scums and vegetation. The science algorithm extends the atmospheric correction by incorporating the spherical shell modelling of Rayleigh molecular scattering and automated procedures for aerosol modelling. The new products also require new algorithms, the development of which is in progress. Furthermore, the $1640 \mathrm{~nm}$ and HRV bands are investigated to improve atmospheric correction and spatial resolution of the measurements. Generation of Level-3 spatially and temporally binned SEVIRI products is anticipated to facilitate long-term turbidity trend analyses. Further opportunities lie in the combined use of SEVIRI with dedicated ocean colour polar observations.

The current development stage of the SEVIRI water turbidity study is supported by initial algorithm validations. Thorough product validation will complete the study. Validation will include generation and verification of intermediate internal products, as well as inter-comparisons with in situ measurements, simulated data (Nechad et al., 2015), and with products from ocean colour polar observing missions.

Acknowledgements. The authors thank EUMETSAT for supporting the SEVIRI water turbidity development. The BELCOLOUR-2 
and GEOCOLOUR projects of the Belgian Science Policy Office (BELSPO) STEREO programme, the FP7/HIGHROC project (grant no. 606797) funded by the European Community's Seventh Framework Programme and the study on Atmospheric correction at high zenith angle funded by the European Space Agency (contract 4000107111/12/NL/AF) are also gratefully acknowledged for having laid the basis for this development.

Edited by: J. A. Johannessen

\section{References}

Albert, P., Antoniou, Y., Arias, J., Barciela, R., Bonekamp, H., Coppini, G., Figa Saldana, J., Gianni, D., Gorringe, P., Kwiatkowska, E., Lecci, R., and O'Carroll, A.: GMES Marine User Requirements, GMES-PURE Project, deliverable D4.1 (including Database Extract), PURE/DLD/DOC/13/038 v2A, available at: http://gmes-pure.eu/deliverables/public-documents/, last access: 31 March 2014.

Antoine, D. (Ed.): Ocean-Colour Observations from a Geostationary Orbit, report number 12 of the International Ocean Colour Coordinating Group, 2012.

Brockmann C., Stelzer, K., Viel, M., Mangin, A., TornfeldtSorensen, J. V., Stipa, T., Neumann, A., Krawczyk, H., Pi Figueroa, A., Campbell, G., and Bruniquel, J.: Routine Water Quality Services for the Baltic Sea (GMES MarCoast): Conference US/EU-Baltic International Symposium, IEEE/OES, doi:10.1109/BALTIC.2008.4625541, 2008.

CEOS OCR-VC Terms of Reference, available from http://www. ioccg.org/groups/OCR-VC/OCR_ToR_V3.1.pdf (last acces: 22 May 2016), 2013.

Choi, J.-K., Park, Y.-J., Ahn, J.-H., Lim, H.-S., Eom, J., and Ryu, J.-H.: GOCI, the world's first geostationary ocean color observation satellite, for the monitoring of temporal variability in coastal water turbidity, J. Geophys. Res., 117, C09004, doi:10.1029/2012JC008046, 2012.

Desmit, X., Vanderborght, J. P., Regnier, P., and Wollast, R.: Control of phytoplankton production by physical forcing in a strongly tidal, well-mixed estuary, Biogeosciences, 2, 205-218, doi:10.5194/bg-2-205-2005, 2005.

de Vargas, C., Aubry, M. P., Probert, I., and Young, J.: Origin and evolution of coccolithophores: from coastal hunters to oceanic farmers, in: Evolution of primary producers in the sea, edited by: Falkowski, P. G. and Knoll, A. H. , 251-285, 2007.

Ding, K. and Gordon, H. R.: Atmospheric correction of ocean color sensors: effects of the Earth's curvature, Appl. Optics, 33, 70967106, 1994.

Donlon, C.: Sentinel-3 Mission Requirements Traceability Document (MRTD), available at: http://download.esa.int/ docs/EarthObservation/GMES_Sentinel-3_MRTD_Iss-1_ Rev-0-issued-signed.pdf (last access: 22 May 2016), 2011.

Dyer, K. R. and Moffat, T. J.: Fluxes of suspended matter in the East Anglian plume Southern North Sea, Cont. Shelf Res., 18, 1311-1331, 1998.

EUMETSAT: MTG System Requirements Document, available at: http://www.eumetsat.int/website/home/Satellites/ FutureSatellites/MeteosatThirdGeneration/MTGDesign/index. html\#fci (last access: 22 May 2016), 2015.
European Commission: Water Framework Directive 2000/60/EC of the European Parliament and of the Council of 23 October 2000 establishing a framework for community action in the field of water policy, OJL, 327, 1-73, 2000.

European Commission: 56/EC of the European Parliament and of the Council of 17 June 2008 establishing a framework for community action in the field of marine environmental policy (Marine Strategy Framework Directive), Official Journal of the European Union, 164, 19-40, 2008.

Gordon, H. R. and Wang, M.: Retrieval of water-leaving radiance and aerosol optical thickness over the oceans with SeaWiFS: A preliminary algorithm, Appl. Optics, 33, 443-452, 1994.

Govaerts, Y. and Clerici, M.: MSG-1/SEVIRI Solar Channels Calibration, Commissioning Activity Report, EUMETSAT, available at: https://www.eumetsat.int/website/wcm/ idc/idcplg?IdcService=GET_FILE\&dDocName=PDF_TEN_ 040024_SEVIRI-SOLCALIB\&RevisionSelectionMethod= LatestReleased\&Rendition=Web (last access: 22 May 2016), 2004.

Gregg, W. (Ed.): Ocean-Colour Data Merging, report number 6 of the International Ocean Colour Coordinating Group, 2007.

Groom, S. B. and Holligan, P. M.: Remote sensing of coccolithophore blooms, Adv. Space Res., 7, 73-78, 1987.

He, X., Bai, Y., Pan, D., Huang, N., Dong, X., Chen, J., Chen, C.-T. A., and Cui, Q.: Using geo-stationary satellite ocean color data to map the diurnal dynamics of suspended particulate matter in coastal waters, Remote Sens. Environ., 133, 225-239, 2013.

IOCS: International Ocean Colour Science meeting, Darmstadt, Germany, 6-8 May 2013, available at: http://iocs.ioccg.org/ iocs-2013-meeting/splinter-session-agendas/ (last access: 22 May 2016), 2013.

IOCS: International Ocean Colour Science meeting, Darmstadt, San Francisco, USA, 15-18 June 2015, available at: http://iocs.ioccg. org/iocs-2015-meeting/breakout-sessions/ (last access: 22 May 2016), 2015.

Jiang, L. and Wang, M.: Improved near-infrared ocean reflectance correction algorithm for satellite ocean color data processing, Opt. Express, 22, 21657-21678, 2014.

Kaas, H. and Peters, S.: CoBiOS Initial User Requirement Analysis: CoBiOS Deliverable D2.6, Coastal Biomass Observatory Services, 2012.

Kwiatkowska, E. J. and McClain, C. R.: Evaluation of SeaWiFS, MODIS Terra and MODIS Aqua coverage for studies of phytoplankton diurnal variability, Int. J. Remote Sens., 30, 6441-6459, 2009.

Lenhart, H. J., Mills, D. K., Baretta-Bekker, H., van Leeuwen, S. M., der Molen, J. v., Baretta, J. W., Blaas, M., Desmit, X., Kuhn, W., Lacroix, G., Los, H. J., Menesguen, A., Neves, R., Proctor, R., Ruardij, P., Skogen, M. D., Vanhoutte-Brunier, A., and Villars, M.: Predicting the consequences of nutrient reduction on the eutrophication status of the North Sea, J. Marine Syst., 81, 148-170, 2010.

McClain, C. and Meister, G. (Eds.): Mission Requirements for Future Ocean-Colour Sensors, report number 13 of the International Ocean Colour Coordinating Group, 2012.

Meirink, J. F., Roebeling, R. A., and Stammes, P.: Inter-calibration of polar imager solar channels using SEVIRI, Atmos. Meas. Tech., 6, 2495-2508, doi:10.5194/amt-6-2495-2013, 2013. 
Milliman, J. D.: Production and accumulation of calcium carbonate in the ocean: budget of a nonsteady state, Global Biogeochem. Сy., 7, 927-957, 1993.

Mouw, C. B., Greb, S., Aurin, D., DiGiacomo, P. M., Lee, Z., Twardowski, M., Binding, C., Hu, C., Ma, R., Moore, T., Moses, W., and Craig, S. E.: Aquatic color radiometry remote sensing of coastal and inland waters: challenges and recommendations for future satellite missions, Remote Sens. Environ., 160, 15-30, 2015.

Nechad, B., Ruddick, K., Schroeder, T., Oubelkheir, K., BlondeauPatissier, D., Cherukuru, N., Brando, V., Dekker, A., Clementson, L., Banks, A. C., Maritorena, S., Werdell, P. J., Saì, C., Brotas, V., Caballero de Frutos, I., Ahn, Y.-H., Salama, S., Tilstone, G., Martinez-Vicente, V., Foley, D., McKibben, M., Nahorniak, J., Peterson, T., Silioì-Calzada, A., Röttgers, R., Lee, Z., Peters, M., and Brockmann, C.: CoastColour Round Robin data sets: a database to evaluate the performance of algorithms for the retrieval of water quality parameters in coastal waters, Earth Syst. Sci. Data, 7, 319-348, doi:10.5194/essd-7-319-2015, 2015.

Neukermans, G., Ruddick, K., Bernard, E., Ramon, D., Nechad, B., and Deschamps, P.-Y.: Mapping total suspended matter from geostationary satellites: a feasibility study with SEVIRI in the Southern North Sea, Opt. Express, 17, 14029-14052, 2009.

Neukermans, G., Ruddick, K. G., and Greenwood, N.: Diurnal variability of turbidity and light attenuation in the southern North Sea from the SEVIRI geostationary sensor, Remote Sens. Environ., 124, 564-580, 2012.

Park, Y.-J.: KIOST updates on GOCI-I and II missions, International Ocean Colour Science Meeting, San Francisco, available at: http://iocs.ioccg.org/2015/files/TUES-1400-Agency_ ReportPark.pdf (last access: 22 May 2016), 2015.

Ruddick, K., Lacroix, G., Lancelot, C., Nechad, B., Park, Y., Peters, S., and Van Mol, B.: Optical remote sensing of the North Sea, in: Remote Sensing of the European Seas, edited by: Barale, V. and Gade, M., Springer-Verlag, 79-90, 2008.

Ruddick, K., Neukermans, G., Vanhellemont, Q., and Jolivet, D.: Challenges and opportunities for geostationary ocean colour remote sensing of regional seas: a review of recent results, Remote Sens. Environ., 146, 63-76, 2014.

Ryu, J.-H., Han, H.-J., Cho, S., Park, Y.-J., and Ahn, Y.-H.: Overview of Geostationary Ocean Color Imager (GOCI) and GOCI Data Processing System (GDPS), Oc. Sci. J., 47, 223-233, 2012.

Sanden, P. and Håkansson, B.: Long-term trends in Secchi depth in the Baltic Sea, Limnol. Oceanogr., 41, 346-351, 1996.
Schmetz, J., Pili, P., Tjemkes, S., Just, D., Kerkmann, J., Rota, S., and Ratier, A.: An introduction to Meteosat Second Generation (MSG), B. Am. Meteorol. Soc., 83, 977-992, 2002.

Smith, H. E. K. et al.: Predominance of heavily calcified coccolithophores at low $\mathrm{CaCO}_{3}$ saturation during winter in the Bay of Biscay, P. Natl. Acad. Sci., 109, 8845-8849, 2012.

Stelzer, K., Koponen, S., and Heege, T.: FRESHMON-High Resolution Freshwater Monitoring GMES Downstream Services User needs and Standards Summary Document, EC Project Deliverable D2.1.1, 2011.

UN: Conference on Environment and Development, available at: http://www.un.org/geninfo/bp/enviro.html (last access: 22 May 2016), 1992.

Vanhellemont, Q., Neukermans, G., and Ruddick, K.: High frequency measurement of suspended sediments and coccolithophores in European and African coastal waters from the geostationary SEVIRI sensor, in: Proceedings of the EUMETSAT Meteorological Satellite Conference \& 19th American Meteorological Society (AMS) Satellite Meteorology, Oceanography, and Climatology Conference, Vienna, Austria, 16-20 September 2013, session 6, satellite observations of the oceans, http://www.eumetsat.int/website/home/News/ ConferencesandEvents/PreviousEvents/DAT_2027670.html (last access: 22 May 2016), 2013.

Vanhellemont, Q. and Ruddick, K.: Turbid wakes associated with offshore wind turbines observed with Landsat 8, Remote Sens. Environ., 145, 105-115, 2014.

Wagner, S. C., Hewison, T., and Roebeling, R. A.: A review of the strategy for the Meteosat Solar Band calibration, EGU General Assembly, Geophys. Res., 14, EGU2012-7265, 2012.

Wang, M.: Effects of ocean surface reflectance variation with solar elevation on normalized water-leaving radiance, Appl. Optics, 45, 4122-4128, 2006.

Wang, M. and Shi, W.: The NIR-SWIR combined atmospheric correction approach for MODIS ocean color data processing, Opt. Express, 15, 15722-15733, 2007.

Wang, M., Ahn, J.-H., Jiang, L., Shi, W., Son, S.-H., Park, Y.-J., and Ryu, J.-H.,: Ocean color products from the Korean Geostationary Ocean Color Imager (GOCI), Opt. Express, 21, 3835-3849, 2013.

Werdell, P. J, Franz, B. A, Bailey, S. W., Feldman, G. C., Boss, E., Brando, V. E., Dowell, M., Hirata, T., Lavender, S. J., Lee, Z.-P., Loisel, H., Maritorena, S., Mélin, F., Moore, T. S., Smyth, T. J., Antoine, D., Devred, E., Fanton d'Andon, O. H., and Mangin, A.: Generalized ocean color inversion model for retrieving marine inherent optical properties, Appl. Optics, 52, 2019-2037, 2013. 